\title{
Editorial
}

\section{Formación continuada a través de ACTAS}

\section{Continued training through ACTAS}

Durante el año 2008 se produjeron dos hechos decisivos para la historia de ACTAS. Por un lado, en enero, fue incluida en el Science Citation Index Expanded (SCI-E), lo que significaba entrar a formar parte de la selectiva base de datos de revistas científicas a partir de la cual se elabora el Journal Citation Report. Así, el primer factor de impacto de la historia de ACTAS verá la luz a mediados del 2010. Por otra parte, en junio, durante el Congreso Nacional de Urología, celebrado conjuntamente con la Confederación Americana de Urología (CAU), esta última decidió que ACTAS pasaba a ser su revista oficial. No cabe duda de que estos hechos han posicionado a ACTAS en una situación estratégica privilegiada. Por un lado, ACTAS es la única revista en lengua española incluida en el SCI-E. Por otro, se ha convertido en una revista de ámbito internacional con un gran potencial divulgativo, ya que, además de ser accesible para el mundo hispanohablante, está también abierta a los lectores anglosajones, al publicarse en español e inglés en su versión on line.

Para afrontar esta nueva etapa la Junta Directiva de la Asociación Española de Urología (AEU), a instancias de la dirección de ACTAS, aprobó un plan estratégico presentado en la reunión plenaria de noviembre de 2008. En el plan se especificaban todas aquellas acciones concretas a llevar a cabo, y la organización y funcionamiento de recursos disponibles para lograr dos objetivos estratégicos bien definidos:

1. Conseguir el mayor factor de impacto posible.

2. Establecerse como la revista referente de Urología en español de ámbito internacional.

Las líneas estratégicas para lograr el primer objetivo están bien definidas, y son similares a las llevadas a cabo por la mayoría de revistas científicas. En cuanto al segundo objetivo se han diseñado tres líneas de actuación estratégica: a) mejora del servicio que da la revista; b) conseguir una personalidad y línea editorial propias; y c) reforzar el compromiso institucional entre AEU y CAU. Respecto a la primera línea de actuación, la mejor manera que tiene una revista de servir a sus lectores es siendo útil; en este sentido se encuadran dos acciones muy concretas: la traducción de información científica del inglés al español para solventar la barrera lingüística de sus lectores, y la pedagógica mediante la formación continuada acreditada a través de ACTAS.

La formación continuada es un derecho que tienen todos los profesionales urólogos. Por lo tanto, para la AEU representa un deber y un compromiso, como queda reflejado en el capítulo IV del reglamento de la AEU respecto a la oficina de formación continuada. Recientemente, el Dr. Miguel Unda se ha hecho cargo de dicha oficina. Una de sus primeras medidas ha sido desarrollar un programa de formación continuada acreditada a través de ACTAS. Su trabajo, además de eficaz, ha sido tremendamente eficiente. Puesto que, en apenas tres meses, ha conseguido de la SEAFORMEC (Sistema Español de Acreditación de la Formación Médica Continuada) la acreditación del programa de formación continuada a través de artículos publicados en ACTAS.

El sistema de acreditación de la SEAFORMEC supone un excelente aval de calidad, ya que dicha organización está constituida por el Consejo General de colegios Oficiales de Médicos, la Federación de Asociaciones Científico-Médicas de España (FACME), la Conferencia de Decanos de Facultades de Medicina y el Consejo Nacional de Especialidades Médicas. Además, utiliza los mismos procedimientos y baremos que los de la Comisión de Formación Continuada del Sistema Nacional de Salud. Pero, sobre todo, la SEAFORMEC se integra en el sistema de acreditación de la Union Européenne de Médecins Specialistes (UEMS) y ha establecido convenios de colaboración con el Accreditation Council for Continuing Medical Education (ACCME) de EE.UU. y con la American Medical Association (AMA). Estos convenios suponen un gran beneficio para los urólogos españoles y sudamericanos, puesto que los créditos obtenidos son compatibles con otros programas de formación de ámbito regional, nacional e internacional.

En este primer número de ACTAS de 2010 damos comienzo al programa de formación continuada a través de la revista. El programa consiste en contestar 5 preguntas realizadas sobre un artículo seleccionado e identificado con un anagrama específico. El artículo seleccionado para obtener los créditos en este primer número no puede ser más adecuado para los propósitos de formación que se pretende. Se trata de la 
traducción de uno publicado en European Urology sobre la Guía Europea de cáncer vesical invasivo.

El programa de formación continuada a través de ACTAS es un servicio útil, y espero que se consolide; por ello animo a todos los urólogos hispanohablantes a utilizarlo, puesto que cada vez que se contesten las preguntas planteadas no sólo se obtendrá un beneficio en la formación propia, sino que se estará contribuyendo a la consecución de los objetivos marcados en este proyecto común llamado ACTAS.

J.L. Ruiz-Cerdá

Director de AcTAS UROLÓGICAS EsPAÑOLAS

Correo electrónico: Jose.L.Ruiz@uv.es 